\title{
Tracking variations in wetland use by breeding flamingos using stable isotope signatures of feather and blood
}

\author{
Elizabeth Yohannes ${ }^{\mathrm{a}}$, Antoine Arnaud ${ }^{\mathrm{b}}$, Arnaud Béchet ${ }^{\mathrm{b}, *}$ \\ ${ }^{a}$ University of Constance, Limnological Institute, Stable Isotope Lab, Germany \\ ${ }^{\mathrm{b}}$ Centre de recherche de la Tour du Valat, Le Sambuc, Arles, France
}

\section{Keywords:}

stable isotopes

habitat shift

index of isotopic shift

France

Camargue

Bayesian mixing models

saltpans

\begin{abstract}
A B S T R A C T
This study tracks temporal variations in the habitat use of breeding adult greater flamingos (Phoeni copterus roseus) in the Camargue (southern France) using simultaneous sampling of $\delta^{15} \mathrm{~N}, \delta^{13} \mathrm{C}$ and $\delta^{34} \mathrm{~S}$ from feather and blood of chicks at fledging. Camargue flamingos forage in a heterogeneous complex of saltpans, permanent and temporary brackish lagoons, freshwater and euryhaline marshes to provision their chicks over a two month period. Using Bayesian mixing models with diet and tissue specific discrimination factors and invertebrates collected from 23 locations, we investigated whether blood and feather isotopes indicated temporal variations in habitat use relative to salinity and hydroperiod. We also tested whether fledgling body condition could be explained by the isotopic signatures of their tis sues. While $\delta^{13} \mathrm{C}$ and $\delta^{15} \mathrm{~N}$ values did not differ significantly between blood and feather, marked differ ences were apparent in the $\delta^{34} \mathrm{~S}$ values obtained from these tissues. Saltpans (38\%) and freshwater marshes (33\%) appeared to be the main habitats visited by adult birds in the early phase of parental care with use of saline wetlands increasing later in the season (54\%). This habitat shift may be related to the peak of resources in saltpans and the drying up of freshwater and brackish marshes by mid summer. Habitat shift (as expressed in individual shifts in isotope values between feather and blood) was not correlated with offspring age, and differed between individuals. A negative relationship was observed between offspring body condition and feather $\delta^{15} \mathrm{~N}$, indicating that chicks fed from temporary flooded marshes fare better than those provisioned from permanent marshes. Foraging strategies of greater flamingos during parental care were heterogeneous, possibly tracking changes in resource availability as the season progressed and reflecting differences in the competitive ability of parent birds. Given that the Camargue saltpans face closure and the region's temporary wetlands remain threatened, our results emphasize the critical importance of conserving these two key habitats for greater flamingos. Dual tissue, triple stable isotope analysis provides a useful and sensitive means of tracking localized environmental change in this threatened system.
\end{abstract}

\section{Introduction}

Habitat shifts during different life history stages are known to be commonplace among fish (Muñoz and Ojeda, 1998), including freshwater (e.g. Schleuter and Eckmann, 2008), estuarine (e.g. Jackson and Rundle, 2008) and reef (e.g. Wells et al., 2008) species. Such shifts are generally thought to be adaptive strategies to minimize intraspecific competition (Werner and Gilliam, 1984) or to support ontogenetic changes such as growth (Ward Campbell and Beamish, 2005). Similar shifts in resource use are also observed in other species where offspring are supported by

\footnotetext{
* Corresponding author.

E-mail address: bechet@tourduvalat.org (A. Béchet).
}

parental investment, including birds. After chicks have hatched, their increasing energy demands lead to greater food (nutritional) requirements. Parents that feed their offspring must respond to these changes either by increasing the quantity of food supplied (Winkler, 1987; Emms and Verbeek, 1991) or by shifting to more profitable foods (e.g. Cairns, 1987).

Identifying shifts in foraging behaviour during different stages in the reproductive process may have important consequences for delineating habitat use and prioritizing conservation areas (Ramirez et al., 2011; Brittain et al., 2012). However, direct esti mation of habitat use by breeding birds is difficult. Tracking adult birds on their foraging trips usually requires either telemetric methods (Amat et al., 2005) or traditional and time consuming approaches such as marking and resighting (e.g. Béchet et al., 2009). 
An alternative approach to tracking habitat use by breeding birds is to monitor stable isotope ratios of carbon $\left(\delta^{13} \mathrm{C}\right)$, nitrogen $\left(\delta^{15} \mathrm{~N}\right)$ and sulphur $\left(\delta^{34} S\right)$ in multiple tissues obtained from dependent chicks (Quillfeldt et al., 2008). Carbon isotope ratios $\left(\delta^{13} \mathrm{C}\right)$ reflect the source of primary productivity and can be used as indicators of an animal's habitat utilization as well as distinguishing the nutritional composition of diet (e.g. Rubenstein and Hobson, 2004). Enrichment of $\delta^{15} \mathrm{~N}$ with increasing trophic levels provides a means of estimating an organism's relative trophic position (Peterson and Fry, 1987). Sulphur isotope ratios $\left(\delta^{34} S\right)$ provide in formation on dietary protein source and geographical origin (Richards et al., 2003) and have been used to identify patterns relating to the salinity of feeding locations (e.g. Fry and Chumchal, 2011). As dietary nutrients are incorporated at different times depending on growth, metabolism and protein turnover of the tissue considered, different tissues from the same individual may provide information on dietary source at different phases of life history. In the case of birds, whole blood (hereafter blood) is an active tissue and its isotopic signature may represent diet inte grated over weeks to about a month (Bauchinger and McWilliams, 2009), while feather is inert keratin tissue that reflects dietary sources used during feather formation. Analysis of simultaneously acquired samples can therefore reveal both spatial and temporal variations in diet.

This study aimed to investigate temporal variation in habitat use by breeding greater flamingos (Phoenicopterus roseus), a flagship species for the conservation of Mediterranean wetlands (Johnson and Cézilly, 2007; Béchet et al., 2012). During incubation and early chick rearing, breeding adults forage in heterogeneous and complex habitat patches with varying salinity gradients and hydroperiods (Béchet et al., 2009). Chicks are fed by parents for an extended period, being unable to feed by themselves for up to 75 days after hatching, as their bill (which is used as a filter apparatus for feeding) is not sufficiently developed (Jenkin, 1957). At this stage, parents do not regurgitate food for their young, but feed them with secretions from glands located in the digestive tract (Lang, 1963). Young birds fly and become independent 2-3 months (75-90 days) after hatching. Summer drying of marshes during the rearing season may enforce a change in habitat use to effectively exploit available resources. Furthermore, qualitative and quantita tive changes in the dietary needs of developing chicks may trigger temporal variation in adult habitat use. Sex specific habitat pref erences in adults could also lead to temporal variation in chick dietary provenance, because as chicks get older, male parents typically increase the time spent feeding their offspring, while fe males do not (Cézilly et al., 1994).

The current study sought to test a hypothesis based on the above observations, that greater flamingos raising offspring exhibit habitat shift. Stable isotope signatures were obtained from samples of two tissue types with varying isotopic turnover rate, namely blood and feather, taken from chicks shortly before fledging. It was expected that feather and blood isotope signatures would allow for the comparison of early ( first month) versus late ( second month) habitat use by parent birds. However, differences in iso topic composition between diet and consumer tissues, also known as discrimination factors (or fractionation factors), are known to restrict direct interpretation of tissue stable isotopes. Usually, discrimination factors are tissue and diet specific (Caut et al., 2009), so applying them independent of tissue or diet isotopic values can bias the interpretation of the results and lead to erro neous conclusions. For this reason, diet and tissue specific discrimination factors were applied to the analyses, as described in Caut et al. (2009), allowing habitat use of breeding greater flamingos to be tracked using simultaneous sampling of feather and blood $\delta^{15} \mathrm{~N}, \delta^{13} \mathrm{C}$ and $\delta^{34} \mathrm{~S}$.
The following predictions were made:

1 if parental habitat use tracks changes in resource availability such that offspring are provisioned from seasonally variable dietary sources, there should be a detectable shift (both in magnitude and direction) in most of the individuals examined, i.e. habitat shifts are adaptive responses to changes in resource availability:

2 if foraging habitat shifts are related to morphological changes in chicks (e.g. growth and physiological maturation), then a strong correlation between chicks age and tissue stable isotope signa tures is to be expected, i.e. habitat shifts are adaptive responses to ontogenetic changes in offspring, such as growth.

This study used triple isotopic models with 5 endpoints of salinity gradient and 3 hydroperiod to investigate whether varia tions in blood and feather stable isotopes indicate population level variations in habitat use with varying salinity and hydroperiod.

\section{Materials and methods}

\subsection{Study species and chick sampling}

Greater flamingos have bred intermittently in the brackish la goons of the Camargue for centuries (Johnson and Cézilly, 2007). Since 1974, successful breeding has taken place on a man made island on the Fangassier lagoon $\left(43^{\circ} 25^{\prime} \mathrm{N}, 4^{\circ} 37^{\prime} \mathrm{E}\right)$, part of the 11,000 ha commercial saltpans of Salin de Giraud (Fig. 1). A single egg is usually laid in April and the laying period is spread over 3074 days. Both parents incubate and feed the chick and incubation lasts 29 days. When chicks are about three weeks old, they form a crèche (Tourenq et al., 1995) where they remain until fledging, 7590 days after hatching.

In 2010, 45 flamingo chicks were caught just prior to fledging on day 79 (4th of August) after first egg hatching. The following year, a further 12 chicks were captured on day 66 (27th of July 2011). Each bird was ringed with a band bearing a unique alphanumeric code. Tarsus length was measured and body weight determined using a 0-5000 g Pesola spring balance. From each chick, a few body feathers were collected and stored dry until required for stable isotope analyses. Blood $(300-500 \mu \mathrm{l})$ was taken from 22 of the 45 birds captured in 2010 and 8 of the 12 birds taken in 2011. Samples were drawn from a vein in the leg soon after capture and kept frozen $\left(80^{\circ} \mathrm{C}\right)$ until required for laboratory analysis.

\subsection{Invertebrate sampling}

In July 2011, samples of greater flamingo prey were collected from 23 adult flamingo foraging locations (Fig. 1; Béchet et al., 2009). In order to minimize bias that could be generated if a mixture of invertebrate prey species were to be sampled at each site, this study focused on one taxon, namely oligochaetes. Oligo chaetes are abundant across the region's wetlands and their iso topic signature is believed to be broadly representative of the habitats they are collected from. Their signatures should therefore allow tracking of parental habitat use during feather and blood cell synthesis in flamingo chicks.

\subsection{Salinity and hydroperiod}

Salinity and hydroperiod are key factors shaping the inverte brate communities of the Camargue wetlands (Waterkeyn et al., 2008). The salinity (as the practical salinity scale) of each sampled wetland was measured in situ in July 2011 by electric conductivity, and varied from 3.6 in freshwater marshes to 114 in 


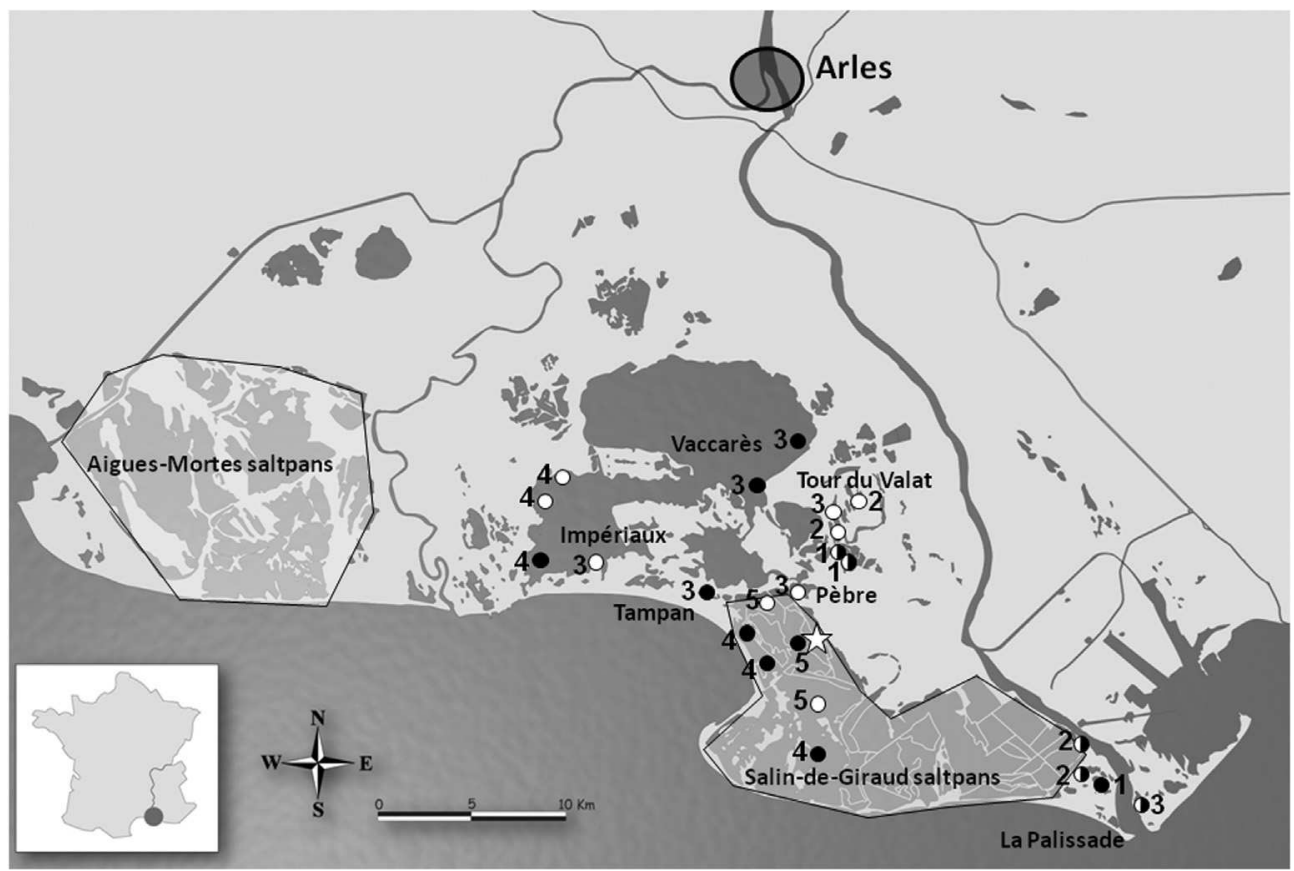

Fig. 1. Greater flamingo breeding colony (white star) and sampling sites (temporary ( $\bigcirc$ ), semi-temporary ( $($ ) and permanent marshes ( $\bullet$ ) along the salinity gradient, classes 1 to 5 ; see text for details) at their main foraging areas within the Camargue wetlands complex.

concentrated saltpans. We defined 5 salinity classes based on changes of macrophyte communities, an important criterion used to describe wetland types for habitat conservation:

Class 1, salinity 0-5: freshwater species (e.g. Myriophyllum spicatum),

Class 2, salinity 5-10: halotolerant species (e.g. Zannichellia pedunculata),

Class 3, salinity 10-30: halophile species of brackish wetlands (e.g. Chara canescens),

Class 4, salinity 30-40: halophile species of salty wetlands (e.g. Ruppia sp., Zostera noltii) and

Class 5, salinity 40-120: saltpans with little or no macrophyte vegetation.

Based on the duration of flooding and irrigation drainage in puts, wetlands were further assigned to one of three hydroperiod groups: temporary, semi temporary (with potential for increases flood duration due to water input from irrigation drainage) and permanently flooded marshes.

\subsection{Laboratory analysis}

We analyzed stable $\delta^{13} \mathrm{C}, \delta^{15} \mathrm{~N}$ and $\delta^{34} \mathrm{~S}$ in blood, feather and representative invertebrate prey. Lipids were removed from each dried, homogenized sample of blood and oligochaetes using a $24 \mathrm{~h}$ 2:1 chloroform methanol solution rinse. This was done because lipids tend to be depleted in ${ }^{13} \mathrm{C}$ relative to whole organisms or tissues, and the lipid content of animal tissue samples can be variable, introducing bias to resulting isotope values (e.g. Peterson and Fry, 1987; Kling et al., 1992). Feather samples were rinsed using methanol solution, washed with distilled water and air dried in a fume hood.

Analysis of $\delta^{13} \mathrm{C}, \delta^{15} \mathrm{~N}$ and $\delta^{34} \mathrm{~S}$ was conducted using sub samples of approximately $0.7 \mathrm{mg}$ for blood, and $0.5 \mathrm{mg}$ for feather and oli gochaetes. Samples were weighed into small tin cups to the nearest $0.001 \mathrm{mg}$, using a micro analytical balance. Samples were then combusted in a Eurovector (Milan, Italy) elemental analyser
(Limnological Institute, University of Constance, Germany). The resulting $\mathrm{CO}_{2}$ and $\mathrm{N}_{2}$ were separated by gas chromatography and passed into a Micromass (Manchester, UK) Isoprime isotope ratio mass spectrometer (IRMS) for determination of ${ }^{13} \mathrm{C} /{ }^{12} \mathrm{C},{ }^{15} \mathrm{~N} /{ }^{14} \mathrm{~N}$ ra tios. Measurements are reported in $\delta$ notation $\left(\delta^{13} \mathrm{C}\right.$ and $\delta^{15} \mathrm{~N}$, respectively) where $\delta \quad 1000 \times\left(R_{\text {sample }} / R_{\text {standard }}\right) 1 \%$ relative to the Pee Dee Belemnite (PDB) for carbon and atmospheric $\mathrm{N}_{2}$ for nitrogen in parts per thousand deviations $(\%)$. Two sulfanilamide (Iso prime internal standards) and two Casein were used as laboratory standards for every 10 unknowns in sequence. The reference material used for sulphur isotope analysis was sulfanilamide, calibrated and traceable to NBS 127 (barium sulphate, $\delta^{34} \mathrm{~S} \quad+20.3 \%$ ). Replicate assays of internal laboratory standards indicate measurement errors (SD) of $\pm 0.05 \%, 0.15 \%$ and $0.05 \%$ for $\delta^{13} \mathrm{C}, \delta^{15} \mathrm{~N}$ and $\delta^{34} \mathrm{~S}$, respectively.

\subsection{Habitat signatures}

Generalized linear models with an identity link and a normal error distribution were used to evaluate whether stable isotope ratios of oligochaetes (response variable) could be explained by salinity class or hydroperiod. Model selection was based on the $\mathrm{AIC}_{\mathrm{C}}$ criterion for small sample size (Burnham and Anderson, 2002). AIC is presented as weight $\left(\mathrm{AIC}_{\mathrm{C}} \omega\right)$, reflecting the weight of evidence for a model being the best model for the data at hand.

\subsection{Discrimination factor}

Mizutani et al. (1992) estimated feather $\delta^{13} \mathrm{C}$ and $\delta^{15} \mathrm{~N}$ isotope discrimination factors for greater flamingos fed on a pellet diet as $\Delta^{13} \mathrm{C} \quad 3.6 \pm 0.6 \%$ and $\Delta^{15} \mathrm{~N} \quad 5.6 \pm 0.3 \%$. However, these esti mates fall outside the range of published values for other birds (e.g. Caut et al., 2009), especially with respect to $\Delta^{15} \mathrm{~N}$. Hence, we preferred to use the approach of Caut et al. (2009), estimating blood and feather discrimination factors for both carbon and nitrogen from a meta analysis incorporating the effect of diet. Accordingly, discrimination factors for feather $\delta^{13} \mathrm{C}$ and for feather and blood $\delta^{15} \mathrm{~N}$ are independent of diet. This meant that for feather $\Delta^{13} \mathrm{C}$ and 
for feather and blood $\Delta^{15} \mathrm{~N}$, a constant discrimination factor could be applied across salinity and hydroperiod classes (Table 1; Caut et al., 2009).

For analysis of blood $\Delta{ }^{13} \mathrm{C}$, the equation provided by Caut et al. (2009) was applied:

$\Delta^{13} \mathrm{C} \quad 0.199 \cdot \delta^{13} \mathrm{C} 3.289$, where $\delta^{13} \mathrm{C}$ is the average dietary iso topic ratio for a given salinity or a given hydroperiod class (Table 1 ).

The approach of Florin et al. (2011) was used to estimate the sulphur discrimination factor $\left(\Delta^{34} S\right)$ for blood and feather, wherein $\Delta^{34} \mathrm{~S}$ is expressed as a function of $\delta^{34} \mathrm{~S}$ along salinity and hydro period gradients: $\Delta^{34} S \quad 0.26 \cdot \delta^{34} S+1.16$, where $\delta^{34} S$ is the average dietary isotopic ratio for a given salinity class (Table 1 ).

\subsection{Dietary reconstitution}

In order to reconstitute dietary isotopic signatures from tissue isotope signatures, it is necessary to take discrimination factors into account. The discrimination factor is formulated as:

$\Delta X \quad \delta X_{\text {tissue }} \delta X_{\text {diet }}$

where $\delta X_{\text {tissue }}$ and $\delta X_{\text {diet }}$ are the bird tissue specific and diet specific signatures, respectively.

Following Caut et al. (2009), $\Delta X$ can be expressed as a linear function of $\delta X_{\text {diet }}$ :

$\Delta X \quad a+b \delta X_{\text {diet }}$,

With $b \quad 0$ when $\Delta X$ is diet independent. $\delta X_{\text {diet }}$ can then be reconstituted from Equations (1) and (2) as

$\delta X_{\text {diet }} \quad \frac{\delta X_{\text {tissue }} a}{1 \quad b}$.

Using Equation (3), isotope values for diet were reconstituted from feather or blood signatures and compared to the actual (raw) isotopic signature of available oligochaete prey. Individual differ ences in tissue stable isotopes were calculated by applying paired $t$ test and Spearman rank correlations for blood and feathers using either actual (raw) signatures or reconstituted dietary values for each isotopic element.

\subsection{Isotopic shift and habitat use}

We calculated an Index of Isotopic shift (IIS) that measures the difference between blood and feather stable isotope ratios:

Table 1

Discrimination factors $(\%)$ for feather and blood of greater flamingo chicks depending on salinity and hydroperiod.

\begin{tabular}{llrll}
\hline & Salinity & \multicolumn{1}{c}{$\Delta^{13} \mathrm{C}$} & \multicolumn{1}{l}{$\Delta^{15} \mathrm{~N}$} & \multicolumn{1}{l}{$\Delta^{34} \mathrm{~S}$} \\
\hline Blood & 0 & $1.22 \pm 0.48$ & $2.25 \pm 0.20$ & $-2.27 \pm 1.02$ \\
& 5 & $0.86 \pm 0.43$ & $2.25 \pm 0.20$ & $-2.95 \pm 1.13$ \\
& 10 & $-0.18 \pm 0.75$ & $2.25 \pm 0.20$ & $-2.99 \pm 1.24$ \\
& 30 & $-1.06 \pm 0.45$ & $2.25 \pm 0.20$ & $-1.79 \pm 0.95$ \\
Feather & 40 & $-1.10 \pm 0.45$ & $2.25 \pm 0.20$ & $-2.53 \pm 1.41$ \\
& 0 & $2.16 \pm 0.35$ & $3.84 \pm 0.26$ & $-2.27 \pm 1.02$ \\
& 5 & $2.16 \pm 0.35$ & $3.84 \pm 0.26$ & $-2.95 \pm 1.13$ \\
& 10 & $2.16 \pm 0.35$ & $3.84 \pm 0.26$ & $-2.99 \pm 1.24$ \\
& 30 & $2.16 \pm 0.35$ & $3.84 \pm 0.26$ & $-1.79 \pm 0.95$ \\
& 40 & $2.16 \pm 0.35$ & $3.84 \pm 0.26$ & $-2.53 \pm 1.41$ \\
\hline \multirow{5}{*}{ Blood } & Hemporary & $-0.48 \pm 0.96$ & $2.25 \pm 0.20$ & $-2.40 \pm 1.05$ \\
& Semi-temporary & $-0.70 \pm 0.64$ & $2.25 \pm 0.20$ & $-2.78 \pm 1.03$ \\
& Permanent & $-0.02 \pm 1.11$ & $2.25 \pm 0.20$ & $-2.63 \pm 1.39$ \\
Feather & Temporary & $2.16 \pm 0.35$ & $3.84 \pm 0.26$ & $-2.40 \pm 1.05$ \\
& Semi-temporary & $2.16 \pm 0.35$ & $3.84 \pm 0.26$ & $-2.78 \pm 1.03$ \\
& Permanent & $2.16 \pm 0.35$ & $3.84 \pm 0.26$ & $-2.63 \pm 1.39$ \\
\hline
\end{tabular}

$\mathrm{I}_{\mathrm{IS}-\mathrm{C}} \quad \delta^{13} \mathrm{C}$ blood $\quad \delta^{13} \mathrm{C}$ feather

I IS-N $\quad \delta^{15} \mathrm{~N}$ blood $\quad \delta^{15} \mathrm{~N}$ feather

$\mathrm{I}_{\mathrm{IS}-\mathrm{S}} \quad \delta^{34} \mathrm{~S}$ blood $\quad \delta^{34} \mathrm{~S}$ feather

If adults feed younger and older chicks from different dietary sources, any resulting shift in isotopic values should correlate with chick age. Since there was no a priori hypothesis on the exact shape of this relationship, Spearman rank correlations were used to explore whether chick age (represented by tarsus length) could explain variations in IIS.

Finally, we examined whether differences in stable isotope signatures between blood and feather might be used to indicate population level variations in habitat use relative to salinity and hydroperiod using Bayesian mixing models and package SIAR of $R$ (Parnell et al., 2008; R core team 2012). This required triple isotope $\left(\delta^{13} \mathrm{C}, \delta^{15} \mathrm{~N}\right.$ and $\left.\delta^{34} \mathrm{~S}\right)$ models with 5 endpoints for the salinity gradient and 3 hydroperiod classes, and tissue specific isotopic discrimination factors as detailed in Table 1.

\subsection{Body condition and habitat use}

Scaled body mass index was calculated as a proxy for flamingo chick body condition, according to Peig and Green (2009). Compared to traditional measurements of body condition calcu lated from the residuals of body mass and tarsus length, the scaled body mass index takes better account of the relationship between size and mass. The scaled body mass index is derived from the Thorpe Lleonart model (Thorpe, 1975; Lleonart et al., 2000) with a Standard Major Axis (SMA) regression:

$\widehat{M}_{i} \quad M_{i}\left[L_{0} / L_{i}\right]^{b S M A S}$

where $M_{i}$ and $L_{i}$ are the mass and tarsus length of individual $i$, respectively; $L_{0}$ is an arbitrary value (for instance, the arithmetic mean of tarsus length in the studied population) and $b S M A$ is the slope of SMA regression.

Generalised linear models were used to determine whether scaled body mass could be explained by the isotopic signatures of $\delta^{13} \mathrm{C}, \delta^{15} \mathrm{~N}$ or $\delta^{34} \mathrm{~S}$. Linear models were tested without interactions, with all combinations of reconstituted dietary isotopes as explan atory factors. The best model was selected based on the $\mathrm{AIC}_{\mathrm{C}} \mathrm{cri}$ terion (Burnham and Anderson, 2002). All statistical analyses were conducted using R (R core, 2012).

\section{Results}

\subsection{Habitat signatures}

Oligochaete $\delta^{13} \mathrm{C}$ increased with salinity $\left(\mathrm{AIC}_{\mathrm{c}} \omega\right) \quad 0.92$ for a model retaining only this effect) but did not vary in relation to hydroperiod $\left(\mathrm{AIC}_{\mathrm{c}} \omega \mathrm{\omega} \quad 0.08\right.$ for the same model adding hydro period; Fig. 2a and b). Oligochaete $\delta^{15} \mathrm{~N}$ increased with hydro period $\left(\mathrm{AIC}_{\mathrm{c}} \omega \quad 0.66\right.$ for a model retaining only this effect) but did not vary with salinity $\left(\mathrm{AIC}_{\mathrm{C}} \omega \quad 0.34\right.$ for a null (intercept only) model; Fig. 2c and d). Neither salinity ( $\mathrm{AIC}_{\mathrm{c}} \omega$ 0.02) nor hydro period $\left(\mathrm{AIC}_{\mathrm{c}} \omega\right)$ 0.07) appeared to have any association with oligochaete $\delta^{34} \mathrm{~S}\left(\mathrm{AIC}_{\mathrm{C}} \omega\right.$ ) of the intercept only model 0.90 ; Fig. 2e and f).

\subsection{Diet reconstitution and individual level feather blood isotope comparisons}

Discrimination factors then allowed reconstituting diet from feather and blood raw signatures. While feather and blood isotope 
a)

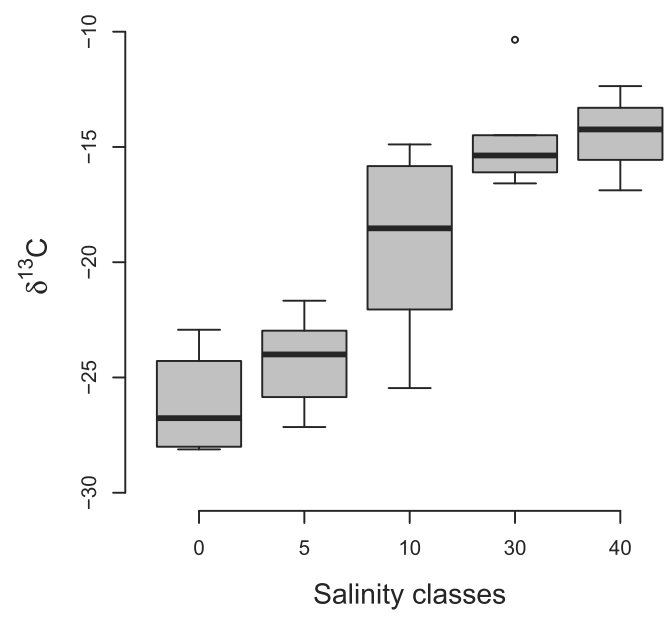

c)

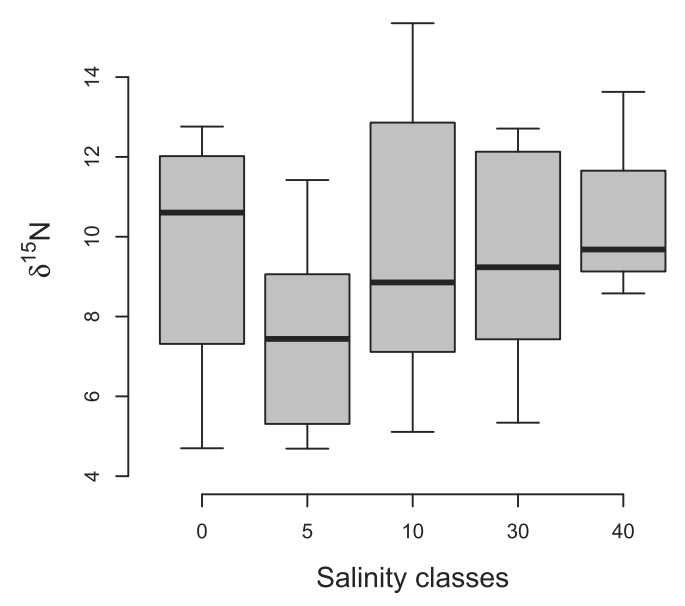

e)

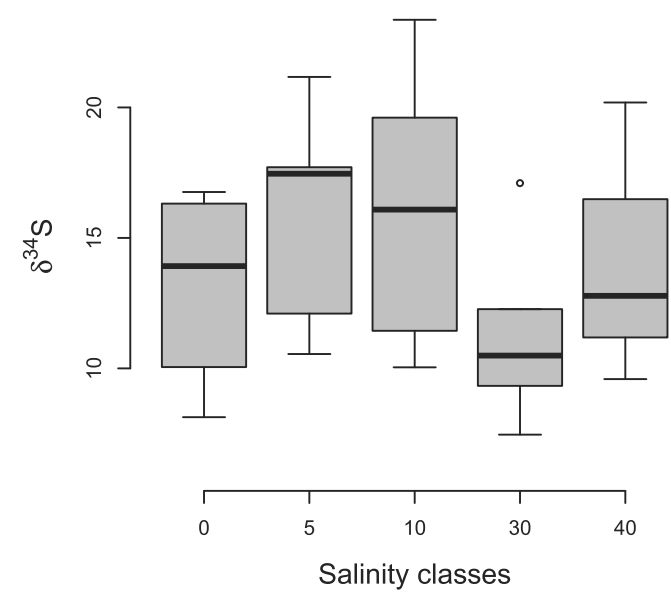

b)

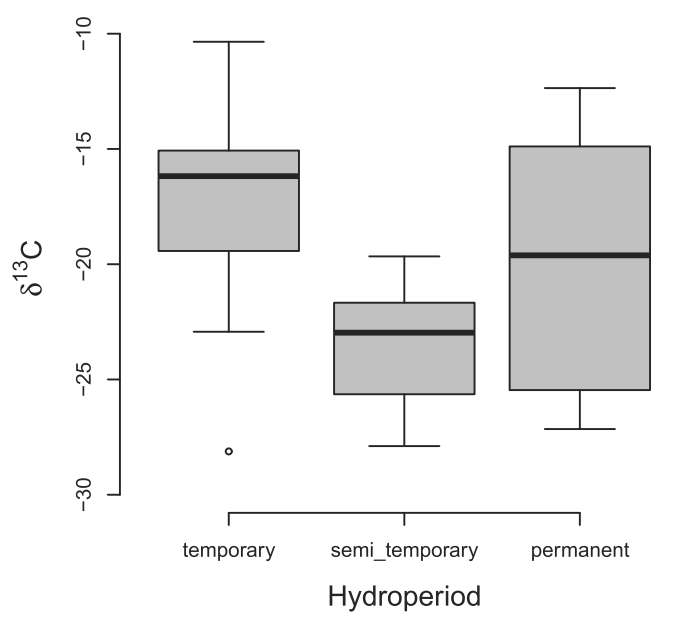

d)

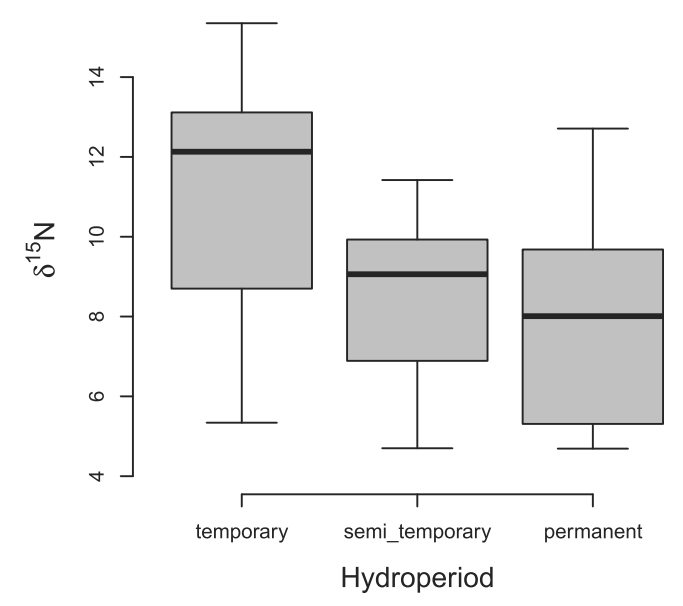

f)

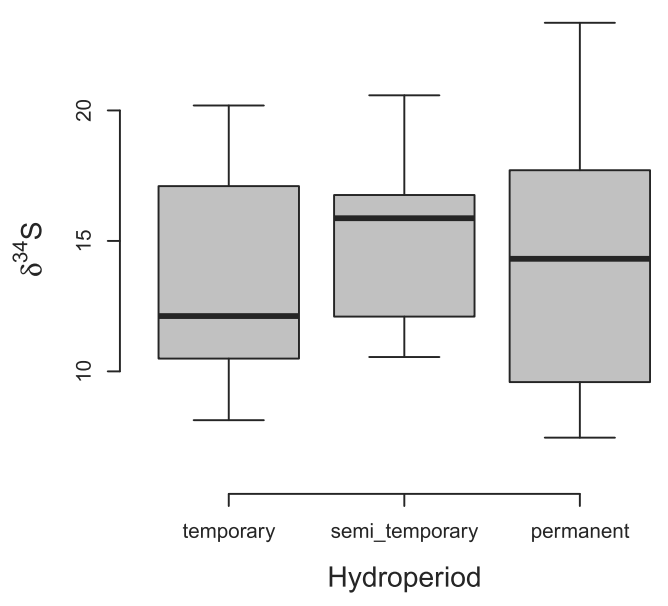

Fig. 2. Variations in oligochaetes $\delta^{13} \mathrm{C}, \delta^{15} \mathrm{~N}$ and $\delta^{34} \mathrm{~S}$ signatures in relation to salinity and hydroperiod.

values differed significantly for all isotopes (Table 2), there was no significant difference in dietary values of $\delta^{13} \mathrm{C}$ and $\delta^{15} \mathrm{~N}$ recon stituted from blood and feather signatures. Reconstituted dietary values for $\delta^{34} \mathrm{~S}$ however varied significantly (Table 2). Blood and feather isotope ratios were correlated for $\delta^{13} \mathrm{C}$ and $\delta^{34} \mathrm{~S}$ but not for $\delta^{15} \mathrm{~N}$ (Table 2).
Using reconstituted dietary values, the $\delta^{13} \mathrm{C}$ isotopic shift for ( $\mathrm{I}_{\mathrm{IS}}$ c) was not significantly different from zero (Table 2). However, $25 \%$ of flamingo chicks exhibited a negative $\mathrm{I}_{\mathrm{IS}-\mathrm{C}}$ of more than $2 \%$ and $17 \%$ of these individuals showed a positive IIS-C greater than $2 \%$ ( IIS- $_{\text {IS }}$ c range [ $9.47 ; 6.94]$ ). Similarly, IIS-N was not significantly different from zero, but $32 \%$ of individuals presented a negative $\mathrm{I}_{\mathrm{IS}-\mathrm{N}}$ of more 
Table 2

Actual isotope signatures of simultaneously sampled feather and blood of greater flamingo chicks and reconstituted dietary values using discrimination factors with paired differences, paired $t$-test and Spearman correlations.

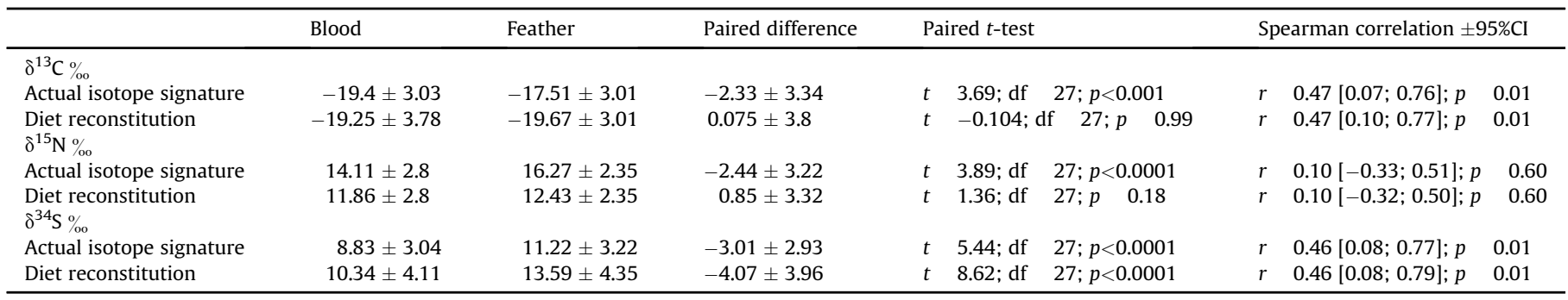

than $2 \%$ and $14 \%$ showed a positive $\mathrm{I}_{\mathrm{IS}-\mathrm{N}}$ greater than $2 \%$ o $\left(\mathrm{I}_{\mathrm{IS}-\mathrm{N}}\right.$ range [ $5.80 ; 6.58])$. In contrast, $\mathrm{I}_{\text {IS-S }}$ was significantly different from zero (Table 2 ), with $78 \%$ of individuals presenting a negative $\mathrm{I}_{\mathrm{IS}-\mathrm{S}}$ of more than $2 \%$ o $\left(\mathrm{I}_{\mathrm{IS}-\mathrm{S}}\right.$ range [ $\left.\left.12.08 ; 6.72\right]\right)$.

For all isotopic elements considered, IIS was independent of tarsus length (Spearman rank correlations: $\delta^{13} \mathrm{C}: r \quad 0.05$ [ 0.3 ; $\left.\begin{array}{lllll}0.46 & 0.76 ; \delta^{15} \mathrm{~N}: r & 0.12 & {[} & 0.54 ; 0.29\end{array}\right], p \quad 0.54 ; \delta^{34} \mathrm{~S}:$ $r \quad 0.21$ [ $0.55 ; 0.17$ ], $p \quad 0.26$ ).

\subsection{Habitat use at the population level as predicted from SIAR} mixing models

At the population level, SIAR mixing models indicated that saltpans of the highest salinity class (38\% [range: $16-54 \%$ ]) and freshwater marshes (33\% [range: $20-45 \%$ ]) were the main hab itats from which adult flamingos provisioned their chicks early in the breeding season (Table 3, Fig. 3a). Interestingly, reliance on salt marshes (in particular class 4 marshes with salinities of 3040) showed a proportional increase towards the end of parental care, such that by the end of the season $>50 \%$ of chick diet originates from habitats in the two highest salinity classes (Table 3, Fig. 3b).

\subsection{Habitat use and body condition of fledglings}

Scaled body mass index decreased with dietary isotope values reconstituted from feather $\delta^{15} \mathrm{~N}$ only $\left(\mathrm{AIC}_{\mathrm{c}} \omega\right) \quad 0.36$ for the model retaining only this effect, $\beta \quad 32.4 \pm 15.4$ ), suggesting that chicks fed from temporary marshes attained higher body condition than those fed from permanent marshes. A model adding $\delta^{13} \mathrm{C}$ could not be discarded $\left(\triangle \mathrm{AIC}_{\mathrm{c}} \quad 0.73 ; \mathrm{AIC}_{\mathrm{c}} \omega \quad 0.26\right)$ and all other models had $\Delta \mathrm{AIC}_{\mathrm{c}}>2$. No such effect was detected using blood isotopic composition, where a model retaining no effect was preferred $\left(\mathrm{AIC}_{\mathrm{c}} \omega \mathrm{1}\right.$ 1.00).

\section{Table 3}

Mean and Bayesian confidence intervals of the probability of habitat use by greater flamingos along salinity and hydroperiod gradients in the Camargue, as modeled from the Bayesian mixing model for feather and blood.

\begin{tabular}{lll}
\hline & Feather & Blood \\
\hline Salinity & & \\
0 & $0.33[0.20 ; 0.45]$ & $0.30[0.13 ; 0.44]$ \\
5 & $0.04[0.001 ; 0.14]$ & $0.05[0.001 ; 0.19]$ \\
10 & $0.14[0.006 ; 0.38]$ & $0.10[0.003 ; 0.31]$ \\
30 & $0.08[0.003 ; 0.26]$ & $0.31[0.05 ; 0.56]$ \\
40 & $0.38[0.16 ; 0.54]$ & $0.23[0.01 ; 0.48]$ \\
Hydroperiod & & \\
Temporary & $0.06[0.002 ; 0.21]$ & $0.11[0.005 ; 0.34]$ \\
Semi-temporary & $0.22[0.07 ; 0.36]$ & $0.15[0.01 ; 0.35]$ \\
Permanent & $0.70[0.51 ; 0.84]$ & $0.73[0.50 ; 0.91]$ \\
\hline
\end{tabular}

\section{Discussion}

Flamingos utilize a wide range of wetlands. Tracing seasonal variations in habitat use within a heterogeneous wetland complex using traditional approaches is almost impossible (but see González Solís et al., 1997; Votier et al., 2003; Takekawa et al., 2009). Several interacting factors mediate seasonal patterns of habitat use in waterbirds. The present study uses intrinsic chemical signals in blood and feather in tandem with those from in vertebrates sampled along gradients of salinity and hydroperiod to provide integrated data on resource acquisition and allocation to offspring.

For all the three elements considered in this study, actual isotope signatures differed significantly between flamingo chick blood and feather. In contrast, dietary values reconstituted from these two tissues differed significantly for $\delta^{34} S$ but not for $\delta^{13} \mathrm{C}$ or $\delta^{15} \mathrm{~N}$. Highlighting the importance of taking into account tissue and diet specific discrimination factors, this result suggests there is no consistent shift in habitat use among greater flamingos between the early and late phases of parental care.

While these results fail to meet our prediction at the population level, presenting no consistent pattern in magnitude or direction, most of the individuals examined did indeed show a seasonal shift in isotope values. A considerable number of individuals showed either positive or negative shifts, indicating that parents do vary the habitats used to provision their offspring as the season progresses. The results also indicate a strong between individual variation in resource acquisition or allocation, but this variation is not related directly to the size of the chicks. Therefore, alternating habitat use by breeding birds is not a simple adaptive response to ontogenetic change (such as chick growth). Indeed, it is likely to be a more complex response, possibly related to individual variation in competitive ability as resources become scarce. In such circum stances, some individuals might focus on a relatively limited frac tion of the available resources, while others track seasonal changes or switch to different resources. Our results support this assump tion, indicating that the utilization of saline marshes increases as the season progresses. This may correspond with resource peaks known to occur in saltpans (e.g. Artemias spp.; Britton and Johnson, 1987) and with the drying up of freshwater and brackish temporary marshes, which typically occurs in late July in the Camargue. These findings have significant conservation implications, underlining the importance of certain seasonally available habitats at critical pe riods in the flamingo breeding cycle.

Our results further confirm the critical importance of saltpans for breeding greater flamingo, up to the point where chicks are fledged (44-54\%; cumulating the two highest salinity classes). The constant water levels maintained in saltpans during summer make them a vital alternative to natural marshes, not only for breeding flamingos but also other coastal waterbirds such as slender billed gulls, especially in dry years (Béchet et al., 2009; Ramirez et al., 
a)

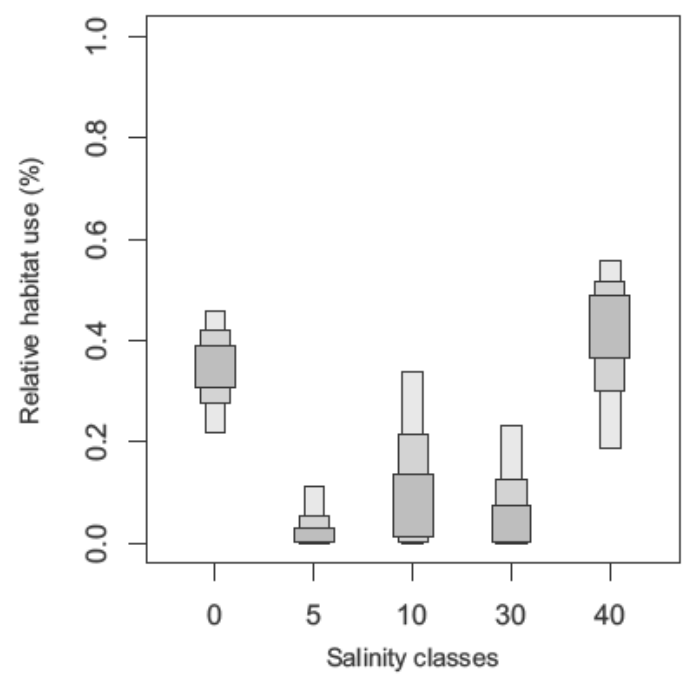

c)

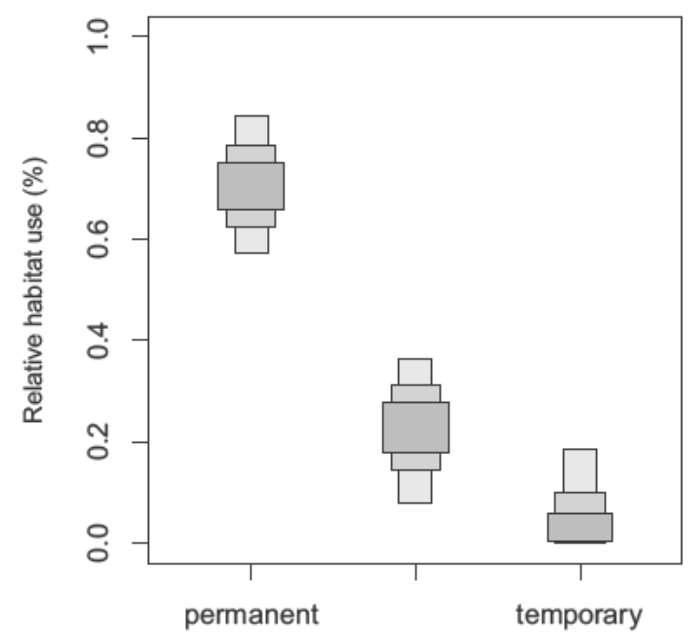

Hydroperiod b)

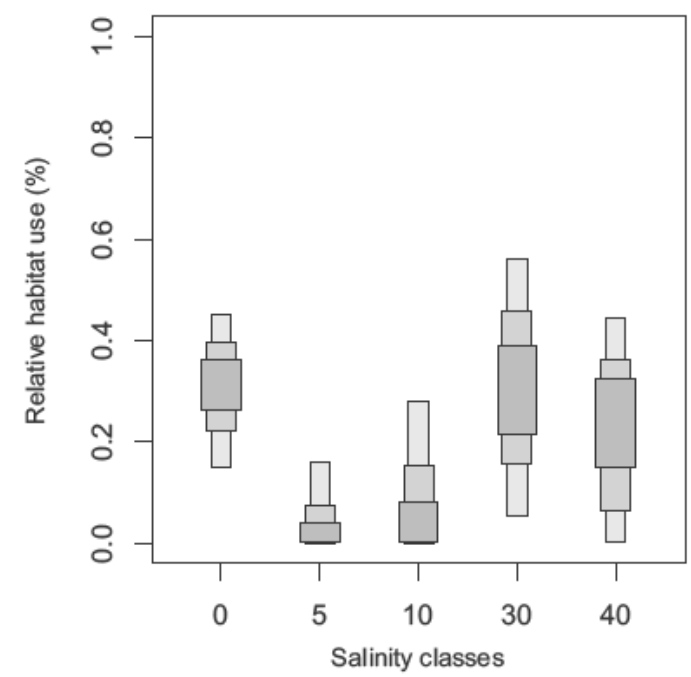

d)

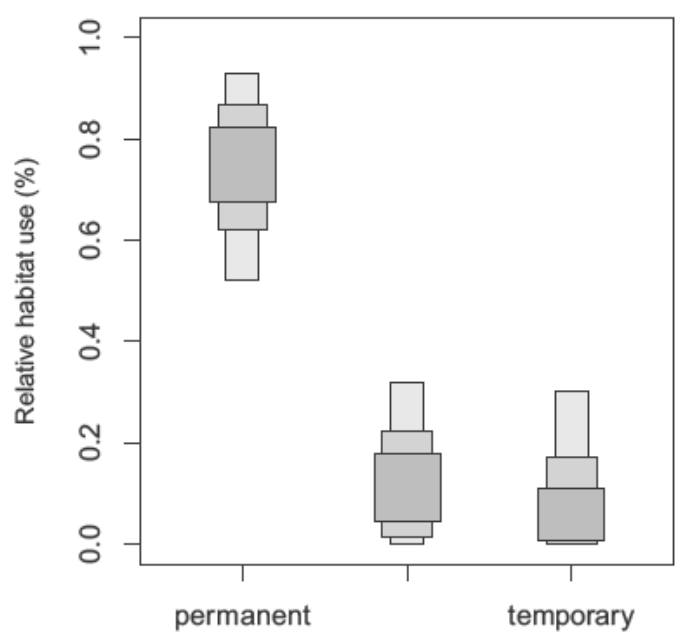

Hydroperiod

Fig. 3. Mixing model estimates of the proportion of habitat used by greater flamingos for chick provision along the salinity gradient in early season (feather isotope signature (a)) and late season (blood isotope signature (b)) and along the hydroperiod gradient in early season (feather (c)) and late season (blood (d)). Bars represent the $50^{\text {th }}, 75^{\text {th }}$ and $95^{\text {th }}$ Bayesian credibility intervals (dark grey, grey, light grey colours, respectively).

2012). In previous work we have used data from dye marked flamingos to show that use of saltpans during the hatching period increases from $18 \%$ in a normal year to $60 \%$ in a drier year (Béchet et al., 2009).

Our results suggest that flamingo chick body condition is negatively related to $\delta^{15} \mathrm{~N}$ signature, suggesting that chicks fed from temporarily flooded marshes fare better than those provisioned from more permanent ones. As temporary marshes dry out, resi dent invertebrates become concentrated to the point where the profitability of foraging matches or exceeds that available in local saltpans. Thus, the apparent trend for increasing use of temporary marshes (from $6 \%$ to $11 \%$ ) during the breeding season could be an adaption allowing parents to maximize the body condition of their chick. As flamingo breeding numbers have been shown to correlate positively with the extent of flooding in natural marshes (Cézilly et al., 1995; Béchet and Johnson, 2008), the positive relationship between chick body condition and temporary marsh use stresses the importance of conserving this habitat. Despite their quality, temporary marshes may remain marginally used because of their decreasing availability in the Camargue in recent decades - the price of increased availability of freshwater and permanent waterbodies (Tamisier and Grillas, 1994). Monitoring of relative habitat use by foraging flamingos suggests that while they have adjusted to this rapid environmental change, this may be at the cost of a lower chick body condition, a trend also found in slender billed gulls (Ramirez et al., 2012).

Oligochaetes, which are widespread among all habitats and known to be part of flamingo diet (Johnson and Cézilly, 2007), were used to provide values of $\delta^{13} \mathrm{C}, \delta^{15} \mathrm{~N}$ and $\delta^{34} \mathrm{~S}$ representing the source of nutrients for feather and blood cell synthesis in chicks. Processing a mixture of prey items independent of relative avail abilities may have produced a wide range of isotope values and made interpretation of the data difficult or misleading. The isotope signatures provided by oligochaete samples fell within the range reported for other flamingo prey found in the Vaccares Lagoon, the largest Camargue wetland (Fig. 1), including copepods, Gammarus sp., Cerastoderma glaucum and Mysis sp. (Persic et al., 2004) and for invertebrates encountered around Fuente de Piedra, the main 
flamingo breeding site in Spain (Rendón et al., 2011). Oligochaete isotope signatures also responded to salinity or hydroperiod gra dients and, for the highest salinity classes, fell within the range of values reported for Artemia sp. in coastal saltpans $\left(\delta^{13} \mathrm{C}\right.$ from 14 to $21 \%$ and $\delta^{15} \mathrm{~N}$ from 1 to $12 \%$; Spero et al., 1993). We are thus confident that using oligochaetes alone as an index of habitat use was a reasonable approach in this study.

In summary, this study has shown that comparing dual tissue, triple stable isotope values with dietary signatures, habitat salinity and hydroperiod constitutes a useful means of tracking habitat use by breeding adult waterbirds. This isotopic approach offers a sen sitive measure of highly localized environmental change, in relation to both salinity and hydrology. The same methodologies might be usefully extended to other wetland communities globally. While the Camargue saltpans are threatened with closure due to eco nomic globalization (Béchet et al., 2012) and temporary wetlands in the region remain threatened by agriculture conversion, tourism and harbour development, our results further emphasize the crit ical importance of conserving permanent and seasonally available habitats for breeding birds including the greater flamingo.

\section{Acknowledgements}

This work was financially supported by Foundation MAVA, Foundation Total and University of Constance, Institute for Limnology. We are grateful to Damien Cohez, Eric Coulet, Gaël Hemery, Jean Baptiste Mouronval, Benjamin Vollot and Claire Tetrel for their help with the sampling of invertebrates. We have appreciated the help of Birgit Beck and Gabriele Dederer during sample preparation and isotope analysis. Amy Jane Beer, Mark Gillingham and Ioanna Salvarina provided helpful comments on the manuscript. We thank Karl Otto Rothhaupt, Marieke Frassl, Marc C. Jochimsen and members of the stable isotope laboratory for valuable comments and discussions.

\section{References}

Amat, J.A., Rendon, M.A., Rendon-Martos, M., Garrido, A., Ramírez, J.M., 2005. Ranging behaviour of greater flamingos during the breeding and post-breeding periods: linking connectivity to biological processes. Biol. Conserv. 125, 183192.

Bauchinger, U., McWilliams, S.R., 2009. Carbon turnover in tissues of a passerine bird: allometry, isotopic clocks, and phenotypic flexibility in organ size. Physiol. Biochem. Zool. 82, 787797.

Béchet, A., Johnson, A.R., 2008. Anthropogenic and environmental determinants of Greater Flamingo Phoenicopterus roseus breeding numbers and productivity in the Camargue (Rhone delta, southern France). Ibis 150, 6979.

Béchet, A., Germain, C., Sandoz, A., Hirons, G.J., Green, R.E., Walmsley, J.G., Johnson, A.R., 2009. Assessment of the impacts of hydrological fluctuations and salt pans abandonment on Greater flamingos in the Camargue, South of France. Biodivers. Conserv. 18, 15751588.

Béchet, A., Rendón-Martos, M., Rendón, M.A., Amat, J.A., Johnson, A.R., GauthierClerc, M., 2012. Global economy interacts with climate change to jeopardize species conservation: a case study in the Greater flamingo in the Mediterranean and West Africa. Environ. Conserv. 39, 13.

Brittain, R., Schimmelmann, A., Parkhurst, D., Craft, C., 2012. Habitat use by coastal birds inferred from stable carbon and nitrogen isotopes. Estuar. Coast. 35, 633 645.

Britton, R.H., Johnson, A.R., 1987. An ecological account of a Mediterranean Salina: the Salin de Giraud (Southern France). Biol. Conserv. 42, 185230.

Burnham, K.P., Anderson, D.R., 2002. Model Selection and Multimodel Inference: Practical Information-theoretic Approach. Springer-Verlag, New York, p. 488.

Cairns, D.K., 1987. Seabirds as indicators of marine food supplies. Biol. Oceanogr. 5, 261271

Caut, S., Angulo, E., Courchamp, F., 2009. Variation in discrimination factors $\left(\delta^{15} \mathrm{~N}\right.$ and $\delta^{13} \mathrm{C}$ ): the effect of diet isotopic values and applications for diet reconstruction. J. Appl. Ecol. 46, 443453.

Cézilly, F., Tourenq, C., Johnson, A., 1994. Variation in parental care with offspring age in the Greater Flamingo. Condor 96, 809812.

Cézilly, F., Boy, V., Green, R.E., Hirons, G.J.M., Johnson, A.R., 1995. Interannual variation in Greater flamingo breeding success in relation to water levels. Ecology 76, 2026.

Emms, S.K., Verbeek, N.A.M., 1991. Brood size, food provisioning, and chick growth in the pigeon guillemot Cepphus columba. Condor 93, 943995
Florin, S., Felicetti, L., Robbins, C., 2011. The biological basis for understanding and predicting dietary-induced variation in nitrogen and sulphur isotope ratio discrimination. Funct. Ecol. 25, 519526.

Fry, B., Chumchal, M.M., 2011. Sulfur stable isotope indicators of residency in estuarine fish. Limnol. Oceanogr. 56, 15631576.

González-Solís, J., Oro, D., Pedrocchi, V., Jover, L., Ruiz, X., 1997. Bias associated with diet samples in Audouin's gulls. Condor 99, 773779.

Jackson, A.C., Rundle, S.D., 2008. Diet shifts by an estuarine goby (Pomatoschistus microps) in the face of variable prey availability. J. Exp. Mar. Biol. Ecol. 361, 17.

Jenkin, P.M., 1957. The filter-feeding and food of flamingos (Phoenicopteri). Phil. Trans. R. Soc. Lon. Ser. 240, 401493.

Johnson, A.R., Cézilly, F., 2007. The Greater Flamingo. T \& AD Poyser, London, p. 328.

Kling, G.W., Fry, B., O'Brien, W.J., 1992. Stable isotopes and planktonic trophic structure in arctic lakes. Ecology 73, 561566.

Lang, E.M., 1963. Flamingos raise their young on a liquid containing blood. Experientia 19, 532533

Lleonart, J., Salat, J., Torres, G.J., 2000. Removing allometric effects of body size in morphological analysis. J. Theor. Biol. 205, 8593.

Mizutani, H., Fukuda, M., Kabaya, Y., 1992. ${ }^{13} \mathrm{C}$ and ${ }^{15} \mathrm{~N}$ enrichment factors of feathers of 11 species of adult birds. Ecology 73, 13911395.

Muñoz, A.A., Ojeda, F.P., 1998. Guild structure of carnivorous intertidal fishes of the Chilean coast: implications of ontogenetic dietary shifts. Oecologia 114,563 573.

Parnell, A., Inger, R., Bearhop, S., Jackson, A.L., 2008. Stable Isotope Analysis in R (SIAR). http://cran.r-project.org/web/packages/siar/index.html.

Peig, J., Green, A.J., 2009. New perspectives for estimating body condition from mass/length data: the scaled mass index as an alternative method. Oikos 118 , 18831891.

Peterson, B.J., Fry, B., 1987. Stable isotopes in ecosystem studies. Annu. Rev. Ecol. Syst. 18,293320

Persic, A., Roche, H., Ramade, F., 2004. Stable carbon and nitrogen isotope quantitative structural assessment of dominant species from the Vaccares Lagoon trophic web (Camargue Biosphere Reserve, France). Estuar. Coast. Shelf Sci. 60, 261272.

Quillfeldt, P., Bugoni, L., McGill, R., Masello, J., Furness, R., 2008. Differences in stable isotopes in blood and feathers of seabirds are consistent across species, age and latitude: implications for food web studies. Mar. Biol. 155, 593598.

R Development Core Team, 2012. R: a Language and Environment for Statistical Computing. R Foundation for Statistical Computing, Vienna, Austria, ISBN 3900051-07-0. URL: http://www.R-project.org/.

Ramirez, F., Abdennadher, A., Sanpera, C., Jover, L., Wassenaar, L., Hobson, K., 2011. Assessing waterbird habitat use in coastal evaporative systems using stable isotopes $\left(\delta^{13} \mathrm{C}, \delta^{15} \mathrm{~N}\right.$ and $\left.\delta \mathrm{D}\right)$ as environmental tracers. Estuarine. Coast. Shelf Sci. 92, 217222.

Ramírez, F., Navarro, J., Afán, I., Hobson, K.A., Delgado, A., Forero, M.G., 2012. Adapting to a changing world: unraveling the role of man-made habitats as alternative feeding areas for slender-billed gull (Chroicocephalus genei). PLoS One 7, e47551.

Rendón, M., Rendón-Martos, M., Garrido, A., Amat, J., 2011. Greater flamingos Phoenicopterus roseus are partial capital breeders. J. Avian Biol. 42, 210213.

Richards, M., Fuller, B., Sponheimer, M., Robinson, T., Ayliffe, L., 2003. Sulphur isotopes in palaeodietary studies: a review and results from a controlled feeding experiment. Int. J. Osteoarchaeol. 13, 3745.

Rubenstein, D.R., Hobson, K.A., 2004. From birds to butterflies: animal movement patterns and stable isotopes. Trend. Ecol. Evol. 19, 256263.

Schleuter, D., Eckmann, R., 2008. Generalist versus specialist: the performances of perch and ruffe in a lake of low productivity. Ecol. Freshw. Fish 17, 8699.

Spero, H., Andreasen, D., Sorgeloos, P., 1993. Carbon and nitrogen isotopic composition of different strains of Artemia sp. Int. J. Salt Lake Res. 2, 133139.

Takekawa, J.Y., Miles, A.K., Tsao-Melcer, D.C., Schoellhamer, D.H., Fregien, S., Athearn, N.D., 2009. Dietary flexibility in three representative waterbirds across salinity and depth gradients in salt ponds of San Francisco Bay. Hydrobiologia 626, 155168.

Tamisier, A., Grillas, P., 1994. A review of habitat changes in the Camargue an assessment of the effects of the loss of biological diversity on the wintering waterfowl community. Biol. Conserv. 70, 3947.

Thorpe, R.S., 1975. Quantitative handling of characters useful in snake systematics with particular reference to intraspecific variation in the Ringed Snake Natrix natrix (L.). Biolog. J. Linn. Soc. 7, 2743.

Tourenq, C., Johnson, A.R., Gallo, A., 1995. Adult aggressiveness and crèching behavior in the Greater flamingo, Phoenicopterus ruber roseus. Colon. Waterbirds 18, 216221.

Votier, S.C., Bearhop, S., MacCormick, A., Ratcliffe, N., Furness, R.W., 2003. Assessing the diet of Great Skuas, Catharacta skua, using five different techniques. Polar. Biol. 26, 2026.

Ward-Campbell, B.M.S., Beamish, F.W.H., 2005. Ontogenetic changes in morphology and diet in the snakehead, Channa limbata, a predatory fish in western Thailand. Environ. Biol. Fishes 72, 251257.

Waterkeyn, A., Grillas, P., Vanschoenwinkel, B., Brendonck, L., 2008. Invertebrate community patterns in Mediterranean temporary wetlands along hydroperiod and salinity gradients. Freshw. Biol. 53, 18081822.

Wells, B.K. Grimes, C.B., Sneva, J.G., McPherson, S., Waldvogel, J.B., 2008. Relationships between oceanic conditions and growth of Chinook salmon (Oncorhynchus tshawytscha) from Alaska, Washington, and California, USA. Fish. Oceanogr. 17, 101125

Werner, E.E., Gilliam, J.F., 1984. The ontogenetic niche and species interactions in size-structured populations. Annu. Rev. Ecol. Syst. 15, 393425.

Winkler, D.W., 1987. A general model for parental care. Am. Nat. 130, 526543. 